УДК 552.5

\title{
Комплексная методика исследования нефтесодержащих горных пород
}

\author{
К.П. Казымов, А.Н. Багаев, В.М. Жданов
}

Пермский государственный национальный исследовательский университет, 614990, Пермь, ул. Букирева, 15. E-mail: mineral @ psu.ru

(Статья поступила в редакиию 4 апреля 2015 г.)

Развитие современных аппаратных и программных средств исследования природных объектов открывает перед исследователями различных областей фундаментальной и прикладной геологии широкие возможности для разработки качественно новых методик анализа вещественного состава горных пород, изучения их физико-химических характеристик с последующим созданием цифровых моделей исследуемых объектов. Описана комплексная методика исследования нефтесодержащих горных пород, которая позволила совместить стандартные методы исследования пород-коллекторов (макроскопические, оптические, определение пористости и фильтрационных свойств методом прокачки и т.п.) с новейшими методами исследования на сканирующем электронном микроскопе, рентгеновском томографе высокого разрешения (до 3 мкм), термоанализаторе и т.п. Предложена цифровая модель образцов карбонатного и терригенного состава, по своим характеристикам отвечающая исходным. Критерием истинности разработанных моделей явились данные петрофизических исследований, полученные прямым экстрагированием, с определением открытой пористости и проницаемости по газу. Разработанные модели позволяют прогнозировать интенсивность протекания различных процессов как природного характера, так и связанных с деятельностью человека.

Ключевые слова: коллекторы нефти и газа, рентгеновский томограф, компьютерное моделирование, пористость и проницаемость.

DOI: $10.17072 / p s u . g e o l .27 .17$

При исследовании горных пород использовано новейшее программное обеспечение для комплексного анализа физико-химических свойств породколлекторов с последующей разработкой математических моделей, характеризующих соотношение «матрикс - поровое пространство» для каждого конкретного образца с возможностью дальнейшего использования полученных результатов в прикладной нефтяной геологии. К ним могут быть отнесены модели резервуаров, оценки фазовой проницаемости, разра- ботка методики воздействия на пластколлектор и т.д.

Были исследованы 30 стандартных образцов керна диаметром 30 мм и высотой 30 мм из скважин двух нефтяных месторождений Пермского края, их них - 15 образцов карбонатного состава (известняки) и 15 образцов терригенных горных пород.

Алгоритм проведения исследований представляет собой последовательное выполнение минералого-петрографических, термогравиметрических, электронно-микроскопических, рентгеноструктурных и

(c) Казымов К.П., Багаев А.Н., Жданов В.М., 2015 
рентгено-томографических исследований, результаты которых обрабатывались программой «Анализатор фрагментов микроструктуры твердых тел» в конфигурации «SIAMS FC» («SIAMS», Россия).

Макро - и микроскопическое описание шлифов позволило получить априорную информацию о минералогическом составе пород-коллекторов, типе и характере це- ментации, процентном соотношении матрикс-цемент, оценить объем порового пространства (рис.1, 2, примеры).

Данные рентгеноструктурного и термического анализов дали возможность определить массовое соотношение основных породообразующих минералов и цементирующего материала (табл.1, 2).
A

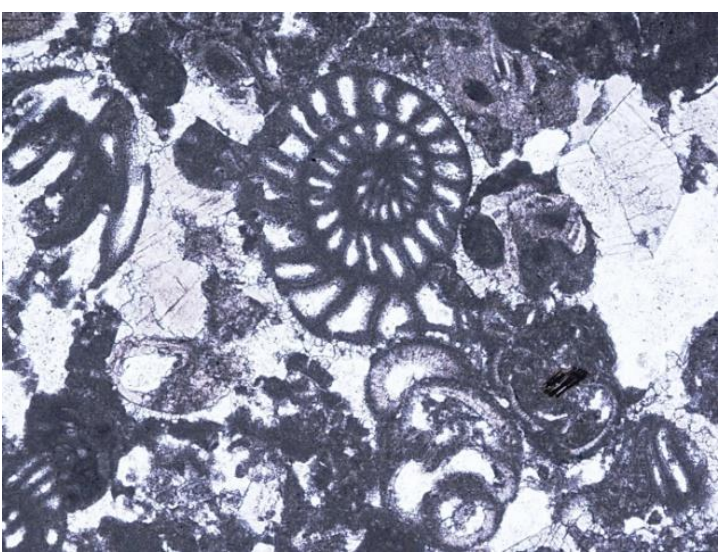

Б

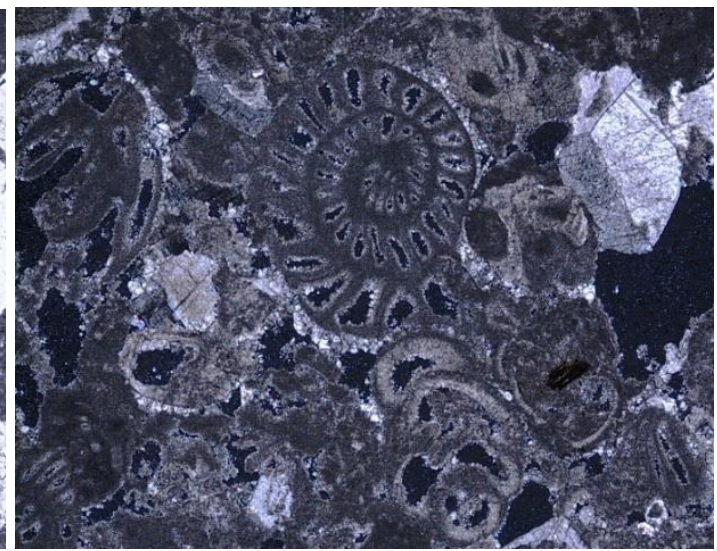

Рис. 1. Биоморфный цельнораковинный известняк (фораминиферовый): A-хоромо сохранившиеся крупные раковины фораминифер, на долю которых приходится более $50 \%$ площади шлифа, николи II; Б- то же самое в скрещенных николях (увеличение $50^{\mathrm{x}}$, ширина - 2,6 мм)
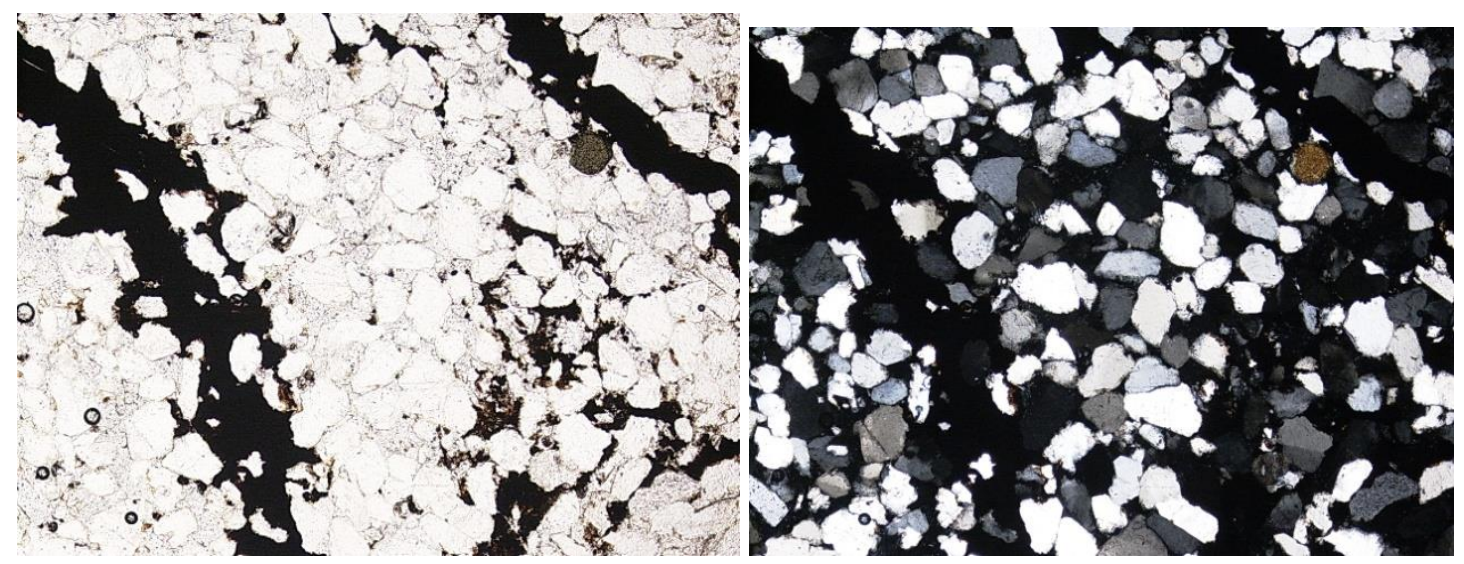

Рис. 2. Шлиф № 136309. Песчаник полевошпат-квариевый: А - трещинки заполнены битуминозным веществом, наблюдается единичное зерно амфибола, один николь; Б-скрещенные николи (увеличение $50^{\mathrm{x}}$, иирина - 2,6 мм)

Использование сканирующего электронного микроскопа с ЭДС приставкой позволило определить размеры и морфологию пор, минеральный состав цемента, оценить «чистоту» внутренней поверхности порового пространства, диагностировать минеральный состав, структуру образований на стенках пор. Результаты элек- тронно-сканирующей микроскопии позволяют оценить размеры пор и наличие или отсутствие вторичных новообразований. Полученные результаты были использованы при калибровке векторной модели терригенных образцов в процессе обработки материалов томографических исследований (рис. 3, 4; табл. 3). 
Таблица 1. Минеральный состав фаз терригенных образиов, мас. \%

\begin{tabular}{|c|c|c|c|c|c|c|c|c|c|c|}
\hline $\begin{array}{c}\text { № } \\
\text { п/п }\end{array}$ & $\begin{array}{l}\text { № об- } \\
\text { разца }\end{array}$ & Кварц & $\begin{array}{l}\text { Калие- } \\
\text { вой- } \\
\text { вой } \\
\text { шпат }\end{array}$ & $\begin{array}{l}\text { Као- } \\
\text { ли- } \\
\text { нит }\end{array}$ & $\begin{array}{l}\text { Гид- } \\
\text { ро- } \\
\text { слю- } \\
\text { да }\end{array}$ & $\begin{array}{l}\text { Каль- } \\
\text { цит }\end{array}$ & $\begin{array}{l}\text { Доло- } \\
\text { мит }\end{array}$ & $\begin{array}{l}\text { Си- } \\
\text { дерит }\end{array}$ & $\begin{array}{l}\text { Пи- } \\
\text { рит }\end{array}$ & $\begin{array}{l}\text { Сум- } \\
\text { ма }\end{array}$ \\
\hline 1 & 136285 & 89.9 & - & - & - & - & - & - & 10.1 & 100 \\
\hline 2 & 136304 & 79.8 & 3.3 & - & - & 5.8 & - & 11.1 & - & 100 \\
\hline 3 & 136309 & 100.0 & - & - & - & - & - & - & - & 100 \\
\hline 4 & 136322 & 85.1 & 6.9 & 2.9 & 2.5 & - & - & 2.6 & - & 100 \\
\hline 5 & 136325 & 100.0 & - & - & - & - & - & - & - & 100 \\
\hline 6 & 136328 & 100.0 & - & - & - & - & - & - & - & 100 \\
\hline 7 & 136329 & 100.0 & - & - & - & - & - & - & - & 100 \\
\hline 8 & 136334 & 92,0 & 3.8 & 0.9 & 3.3 & - & - & - & - & 100 \\
\hline 9 & 136337 & 81.6 & 5.4 & 1.7 & 1.1 & 8.2 & - & 2.0 & - & 100 \\
\hline 10 & 136340 & 92.3 & - & - & - & - & - & 7.2 & 0.5 & 100 \\
\hline 11 & 136342 & 96.6 & - & 3.4 & - & - & - & - & - & 100 \\
\hline 12 & 136343 & 93.9 & - & 2.9 & 3.2 & - & - & - & - & 100 \\
\hline 13 & 136345 & 86.5 & - & 1.1 & - & 7.1 & - & - & 5.3 & 100 \\
\hline 14 & 136347 & 94.4 & - & 3.2 & - & - & - & - & 2.4 & 100 \\
\hline 15 & 136350 & 56.9 & 4.0 & - & - & 3.4 & 35.7 & - & - & 100 \\
\hline
\end{tabular}

Таблица 2. Минеральный состав карбонатных образиов, мас. \%

\begin{tabular}{|c|c|c|c|c|c|c|}
\hline № п/п & № цилиндра & Кальцит & Доломит & Кварц & КПШ & Сумма \\
\hline 1 & 139455 & 98.2 & - & 1.8 & - & 100 \\
\hline 2 & 139458 & 95.6 & - & 4.4 & - & 100 \\
\hline 3 & 139461 & 95.9 & 1.7 & 2.4 & - & 100 \\
\hline 4 & 139463 & 95.8 & - & 3.5 & 0.7 & 100 \\
\hline 5 & 139464 & 97.1 & - & 2.9 & - & 100 \\
\hline 6 & 139466 & 95.9 & - & 4.1 & - & 100 \\
\hline 7 & 139471 & 95.2 & - & 4.8 & - & 100 \\
\hline 8 & 139472 & 96.7 & 1.9 & 1.4 & - & 100 \\
\hline 9 & 139481 & 98.5 & - & 1.5 & - & 100 \\
\hline 10 & 139482 & 96.2 & - & 3.8 & - & 100 \\
\hline 11 & 139483 & 90.6 & 7.7 & 1.7 & - & 100 \\
\hline 12 & 139487 & 92.4 & 4.3 & 3.3 & - & 100 \\
\hline 13 & 139497 & 71.2 & 27.2 & 1.6 & - & 100 \\
\hline 14 & 139506 & 93.2 & 4.3 & 2.5 & - & 100 \\
\hline 15 & 139508 & 81.8 & 16.2 & 2.0 & - & 100 \\
\hline
\end{tabular}




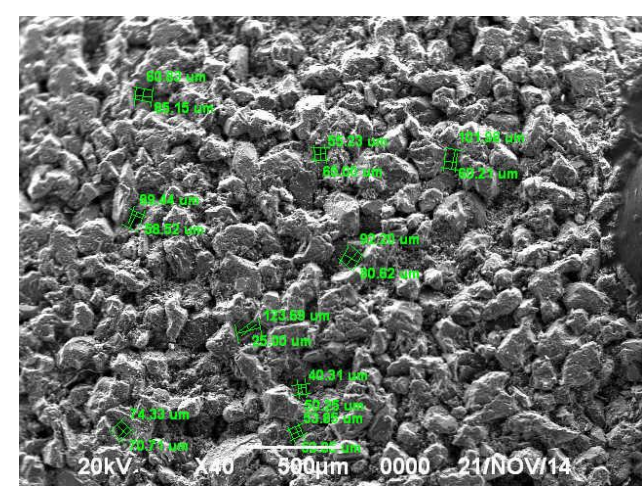

Рис. 3. Распределение пор по ториевой поверхности ичилиндра (обр. № 136309)

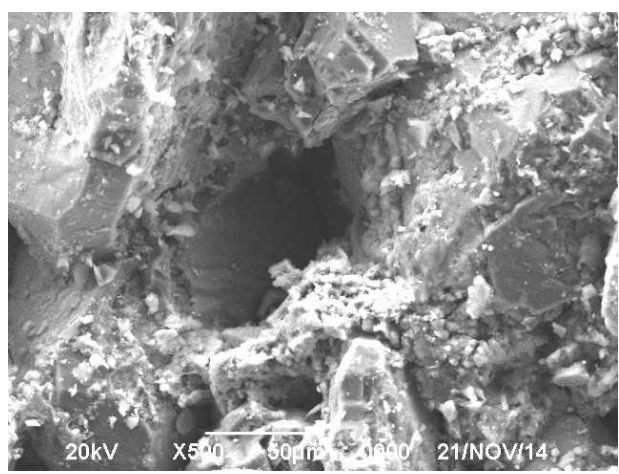

Рис. 4. Внутреннее строение поры (обр. № 136309)

Таблица 3. Химический состав минералов цемента, масс.\%

\begin{tabular}{|c|l|c|c|c|c|c|c|c|c|c|}
\hline $\begin{array}{c}\text { № об- } \\
\text { разца }\end{array}$ & Минерал & $\mathbf{M g O}$ & $\mathrm{Al}_{2} \mathbf{O}_{3}$ & $\mathbf{S i O}_{2}$ & $\mathbf{K}_{2} \mathbf{O}$ & $\mathbf{T i O}_{2}$ & $\mathbf{F e O}$ & $\mathbf{C O}_{2}$ & $\mathbf{C a O}$ & $\begin{array}{c}\text { Сум- } \\
\text { ма }\end{array}$ \\
\hline 136329 & Каолинит & 0.43 & 18.05 & 76.42 & 1.99 & 2.05 & 1.07 & - & - & 100,01 \\
\hline \multirow{2}{*}{136334} & Каолинит & - & 11.53 & 76.27 & 12.2 & - & - & - & - & 99,82 \\
\cline { 2 - 11 } & Опал & - & 1.46 & 98.36 & 0.19 & - & - & - & - & 100,04 \\
\hline 136340 & Каолинит & - & 14.08 & 73.83 & 11.92 & - & 0.18 & - & - & 100,01 \\
\hline 136350 & Кальцит & 16.48 & 0.62 & 6.15 & 0.15 & - & 1.03 & 32.79 & 42.78 & 100,00 \\
\hline
\end{tabular}

Таблица 4. Элементный состав иеемента образиа, масс. \%

\begin{tabular}{|c|c|c|c|c|c|c|c|c|c|c|}
\hline № обр. & Минерал & $\mathbf{O}$ & $\mathbf{M g}$ & $\mathbf{A l}$ & $\mathbf{S i}$ & $\mathbf{S}$ & $\mathbf{K}$ & $\mathbf{T i}$ & $\mathbf{F e}$ & $\begin{array}{c}\text { Сум- } \\
\mathbf{M a}\end{array}$ \\
\hline 136340 & $\begin{array}{c}\text { Пирит с } \\
\text { глиной }\end{array}$ & 40.47 & 0.37 & 3.18 & 6.10 & 31.32 & 1.00 & 0.18 & 16.81 & 100,0 \\
\hline
\end{tabular}

Данные термогравиметрического анализа уточняют и подтверждают с высокой степенью достоверности результаты рентгенофазового, минералого-петрографического, электронно-микроскопического и микрозондового анализов. Были установлены особенности фазового состояния кальцита в известняках (фазовый переход кальцит-доломит, кальцит-магнезит), количественно и качественно диагностирован карбонатный цемент в терригенных породах. Применение томографа позволяет получить объемную растровую модель образца. Использован оригинальный математический алгоритм анализа растрового изображения в комплексе с данными микроописания образцов, результатов электронносканирующей микроскопии, фазового состояния вещества и т.д., разработаны векторные (сетевые) модели для каждого образца керна.

С использованием методики обработки трехмерной векторной модели образцов для каждого из 15 образцов карбонатных пород была составлена цифровая модель, где были определены 2 фазы - поровое пространство и матрикс (рис. 5).

Для контроля качества определения фазового состояния использовались данные определения порового пространства по газу. Результаты сравнительного анализа представлены в табл. 5. 


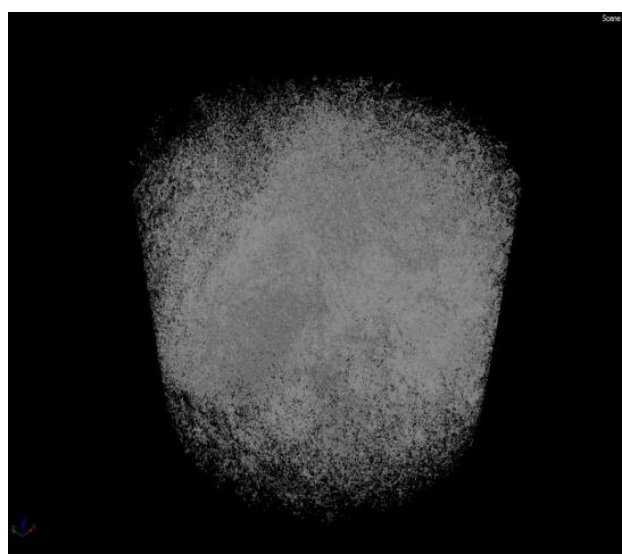

Рис. 5. Визуализачия пустотного пространства образиа № 139506 карбонатных пород: светлые участки - поровое пространство, матрикс не показан

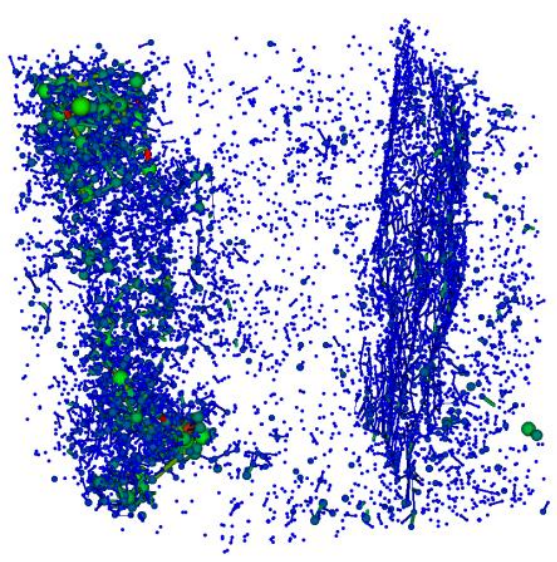

Рис. 6. Фрагмент сетевой модели трещиноватой зоны образиа 139506 (ребро куба 5 мм)

Таблица 5. Сравнение значений порового пространства образиа, полученных лабораторными методами и в результате компьютерной томографии, \%

\begin{tabular}{|c|c|c|c|}
\hline & & \multicolumn{2}{|c|}{ Значения пористости } \\
\hline $\begin{array}{c}\text { № } \\
\text { п/п }\end{array}$ & $\begin{array}{c}\text { № } \\
\text { цилиндра }\end{array}$ & По газу & $\begin{array}{c}\text { По данным компьютерной } \\
\text { томографии }\end{array}$ \\
\hline 1 & 139455 & 9,5 & 9,38 \\
\hline 2 & 139458 & 2,1 & 1,9 \\
\hline 3 & 139461 & 7,4 & 8,2 \\
\hline 4 & 139463 & 14,2 & 12,12 \\
\hline 5 & 139464 & 14,3 & 14,08 \\
\hline 6 & 139466 & 6,8 & 9,6 \\
\hline 7 & 139471 & 13,5 & 15,8 \\
\hline 8 & 139472 & 15,6 & 18,84 \\
\hline 9 & 139481 & 9,8 & 24,12 \\
\hline 10 & 139482 & 15,7 & 9,88 \\
\hline 11 & 139483 & 8,8 & 7,78 \\
\hline 12 & 139487 & 6,4 & 4,1 \\
\hline 13 & 139497 & 3.7 & 8,92 \\
\hline 14 & 139506 & 8,0 & 11,28 \\
\hline 15 & 139508 & 7,6 & \\
\hline
\end{tabular}

Практическое применение разработанной методики имеет широкие перспективы. С помощью программного комплекca SIAMS LabDesk может быть построена сетевая модель порового пространства образца.

Суть обработки растрового изображения сводится к следующему. Каждой поре в растровой модели соответствует сфера в векторной модели, объем которой аналогичен объему поры. Каждый канал, соединяющий поры, моделируется цилин- дром с площадью сечения, равного площади наименьшего сечения канала.

В результате обработки растровой модели создается векторная модель, пример которой представлен на рис. 6, где в правой части сетевой модели образца можно наблюдать наиболее проницаемую зону, связанную с трещиной, рассекающей весь образец. Центральная часть образца является наименее проницаемой. Левая часть сетевой модели отражает внутриформен- 
ные связанные поры органогенного происхождения

В настоящий момент группой учёных из ООО «СИАМС» г. Екатеринбург апробируется программное обеспечение для расчёта относительной фазовой проницаемости (ОФП) с использованием векторной модели и данных комплексного минералогического исследования пород- коллекторов (рис. 7). Исходный материал для расчётов ОФП был получен сотрудниками кафедры минералогии и петрографии ПГНИУ в результате комплексного исследования образцов горных пород, предоставленных ПермНИПИнефть. Следует отметить, что результаты расчёта ОФП требуют верификации утверждёнными методиками.

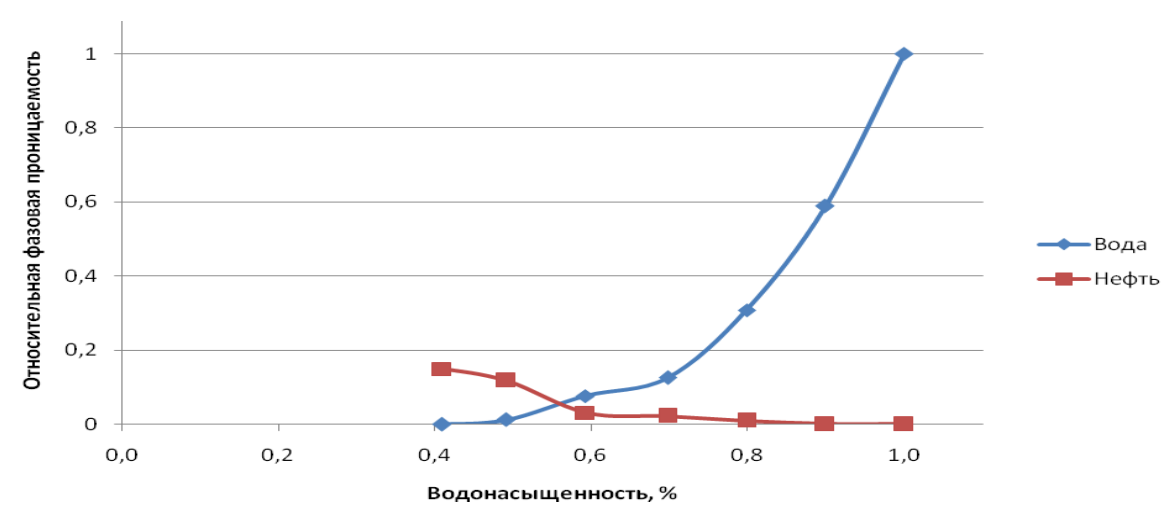

Рис. 7. Относительная фазовая проницаемость образиа № 136342

Для образцов, сложенных тонкодисперсным материалом, где размер пор и каналов слишком мал для разрешения томографа, может быть использован метод моделирования образца горной породы с использованием алгоритмов плотной упаковки несферических выпуклых частиц, в основу которого заложен алгоритм упаковки обломочного

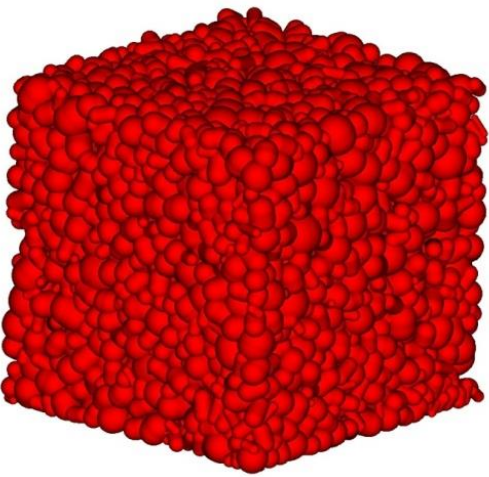

Векторная модель упаковки материала, размер частиц которого получен методом электронной микроскопии (рис. 8).

В табл. 6 и на рис. 8 приведены расчетные параметры проницаемости по осям $\mathrm{X}, \mathrm{Y}, \mathrm{Z}$, а также данные по относительной фазовой проницаемости смоделированного образца.

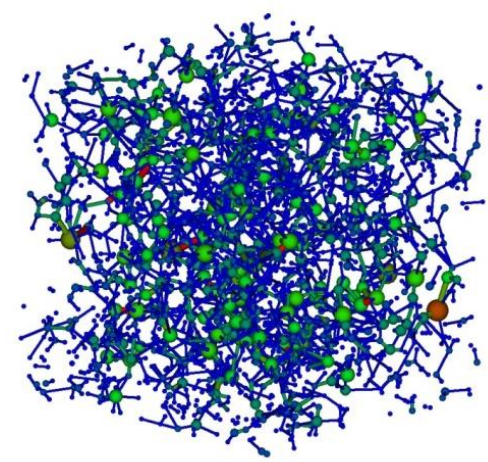

Сетевая модель порового пространства

Рис. 8. Визуализачия результатов моделирования упаковки несферических плотных частии образиа №136337 
Таблица 7. Вычисленная закрытая пористость и абсолютная проницаемость по данным интерпретации микротомографического исследования терригенных образцов

\begin{tabular}{|c|c|c|c|c|}
\hline $\begin{array}{c}\text { № } \\
\text { п/п }\end{array}$ & $\begin{array}{c}\text { Лаб. № } \\
\text { образца }\end{array}$ & $\begin{array}{c}\text { Общая пористость по } \\
\text { 3Dмодели, \% }\end{array}$ & $\begin{array}{c}\text { Закрытая пори- } \\
\text { стостьпо 3Dмодели, } \\
\text { \% }\end{array}$ & $\begin{array}{c}\text { Абсолютная проницае- } \\
\text { мость по 3Dмодели, мД }\end{array}$ \\
\hline 1 & 136285 & 17,9 & 0,4 & 73,3 \\
\hline 2 & 136304 & 14 & 4,1 & 1,7 \\
\hline 3 & 136309 & 20,3 & 0,3 & 2,4 \\
\hline 4 & 136322 & 15,6 & 0,9 & 103,4 \\
\hline 5 & 136325 & 21,8 & 0,3 & 249,2 \\
\hline 6 & 136328 & 21,2 & 0,3 & 119,1 \\
\hline 7 & 136329 & 20,6 & 0,3 & 17,8 \\
\hline 8 & 136334 & 18,1 & 0,3 & 0,6 \\
\hline 9 & 136337 & 9 & 2,5 & 249,8 \\
\hline 10 & 136340 & 17,1 & 0,6 & 25,6 \\
\hline 11 & 136342 & 19,7 & 0,3 & 4,2 \\
\hline 12 & 136343 & 16,3 & 0,4 & 30,2 \\
\hline 13 & 136345 & 15,8 & 0,4 & 24,0 \\
\hline 14 & 136347 & 15,5 & 0,6 & 0,2 \\
\hline 15 & 136350 & 2,5 & 0,8 & \\
\hline
\end{tabular}

Таблица 6. Характеристика упаковки образиа № 136337

\begin{tabular}{|l|l|}
\hline Направление & Проницаемость, мД \\
\hline Вдоль оси X & 0.456 \\
\hline Вдоль оси Y & 0.509 \\
\hline Вдоль оси Z & 0.754 \\
\hline
\end{tabular}

Одной из задач томографического исследования образцов являлось вычисление закрытой пористости. Для решения данной проблемы использовались несколько оригинальных специализированных программных пакетов в составе:

- SIAMS FC: Трехмерный анализатор изображений внутренней структуры твердых тел ${ }^{1}$;

- SIAMS FC Flow: Симулятор фильтрационных процессов в пористых структурах твердых тел ${ }^{2}$;

- SIAMS FC: 3D Packing of SpherePolyhedra ${ }^{3}$.

\footnotetext{
${ }^{1}$ Свидетельство о государственной регистрации программы для ЭВМ №2014617236 от 16 июля 2014 г.

${ }^{2}$ Свидетельство о государственной регистрации программы для ЭВМ №2014617237 от 16 июля 2014 г.
}

В результате трехмерного и двумерного анализа получены воксельные модели поровых пространств по всем 15 образцам. Воксельные модели поровых пространств далее были преобразованы в сетевые поровые модели, по которым произведены модельные расчеты абсолютной проницаемости (табл. 7).

Дополнительно был проведен анализ томограмм стандартных образцов, полученных перед данным исследованием, на предмет наличия крупных пор, каверн и трещин. Трещины и каверны на образцах цементированы и не участвуют в фильтрации, однако на некоторых образцах (например, 136328) имеются крупные поры размером 100-200 мкм, равномерно распределенные по объему и связанные с более мелкими поровыми каналами.

\section{Выводы}

Совместное использование данных томографии, рентгеноструктурного анализа, электронной спектрометрии, микроописания шлифов и электронно-зондового анализа позволило откалибровать математи-

\footnotetext{
${ }^{3}$ Свидетельство о государственной регистрации программы для ЭВМ №2006610285 от 12января 2006 г.
} 
ческую модель каждого исследуемого образца.

Созданный математический аналог (в пределах возможностей современной приборной базы) горной породы с высокой степенью вероятности отражает реальную картину её внутреннего строения, распределения пор, каналов, их взаимосвязь, влияние минерального состава, гранулометрических характеристик, постгенетических изменений на фильтрационноемкостные характеристики.

Математическое моделирование породы открывает широчайшие возможности практического применения полученных результатов. Данные сетевого моделирования использованы для расчета интенсивности процессов миграции флюидов различного типа (нефть, газ, вода, буровая жидкость) в пласте-коллекторе.

Результаты исследования по определению закрытой пористости пород в виде модельных расчетов в целом согласуются с экспериментальными данными и дают дополнительную информацию о закрытой пористости. Возникшие расхождения между моделью и экспериментом по оценке проницаемости связаны, в первую очередь, с различием в размерах образцов, используемых для компьютерного анализа (3-5 мм), и стандартных образцов. Крупные поры, выявленные при томографическом сканировании стандартных образцов, вносят большой вклад в проницаемость, однако на микрообразцах этот вклад незначителен.

Результаты математического моделирования позволяют рассчитать наиболее эффективные способы воздействия на пласты-коллекторы, оценить эффективность методов технологических операций по увеличению порового пространства, использовать полученные результаты при составлении моделей месторождений, определении наиболее подходящего типа буровых растворов для укрепления стенок скважин и т.д. В дальнейшем возможно на новой основе установить зависимости структурных характеристик от фациаль- ной обстановки, прогнозировать распределение пластов-коллекторов и флюидоупоров по площади, проводить фациальное моделирование.

Работа выполнена сотрудниками Сектора наноминералогии кафедры минералогии и петрографии Пермского государственного национального исследовательского университета с использованием собственного уникального научного аналитического оборудования.

\section{Библиографический список}

1. Горбунов Н.И., Цюрюпа И.Г., Шуригина E.A. Рентгенограммы, термограммы и кривые обезвоживания минералов, встречающихся в почвах и глинах. М.: Изд-во AH CCCP, 1952. $188 \mathrm{c}$.

2. Иванова В.П., Касатов Б.К., Красавина Т.Н., Розинова Е.Л. Термический анализ минералов и горных пород. Л.: Недра, $1974.400 \mathrm{c}$

3. Осовеикий Б.М. Дробная гранулометрия аллювия / Перм. ун-т. Пермь, 1993. 43 с.

4. Осовецкий Б.М., Молоштанова Н.Е. Литология (классификация, методы исследования, описание осадочных пород) / Перм. ун-т. Пермь, 2013. 158 с.

5. Рентгенографический количественный фазовый анализ (РКФА) глинистых минералов (каолинита, гидрослюды, монтморилонита): методические рекомендации №139 / НСОММИ ВИМС. М., 1999.

6. Рыљжиков Н.И., Михайлов Д.Н., Шако В.В. Метод расчёта профилей распределения пористости и объёмных долей материалов в пористой среде с помощью анализа данных рентгеновской микротомографии // Прикладная механика. 2013. Т. 5, № 4. С. 161.

7. Экспрессный рентгенографический полуколичественный фазовый анализ глинистых минералов: методические рекомендации №68 / НСОММИ ВИМС. М., 1991.

8. Kato, Takahashi, Kawasaki and Kaneko Segmentation of multi-phase X-ray computed tomography images. doi: 10.1680/envgeo.13.00036

9. Schluter S., Weller U. and Vogel H-J. Segmentation of X-ray microtomography images of soil using gradient masks // Computers and Geosciences 36: 1246-1251, doi: 10.1016/j.cageo.2010.02.007. 


\title{
Integrated Methodology of Study of the Oil-bearing Rock
}

\author{
K.P. Kazymov, A.N. Bagaev, Zhdanov V.M. \\ Perm State University, 15 Bukireva Str., Perm 614990, Russia \\ E-mail: mineral@psu.ru
}

Recent development of up-to-date instrumental tools and data processing software provides a new opportunity for working out the new methods of rock composition analysis, physico-chemical characteristics study, and further integration the obtained data for making the digital models of geological objects. In the article, we describe the integrated methodology of oil-bearing rock study, which allowed combining conventional methods of study of the reservoir rock (macroscopic, optical, etc.) with up-to-date methods of electron microscopy, X-ray tomography, and thermal analysis. The authors propose the digital model of carbonate and terrigenous samples, which have the same characteristics like the natural material. The correctness of the obtained digital models was confirmed by the petrophysical study of connected porosity and permeability to gas using direct extraction. Developed models allow making the optimal reservoir model, forecasting of the reservoir stimulation methods for increasing the oil recovery.

Keywords: oil and gas reservoirs; X-ray tomograph; computer modeling, porosity and permeability.

\section{References}

1. Gorbunov N.I., Tsyuryupa I.G., Shurigina E.A. 1952. Rentgenogrammy, termogrammy i krivye obezvozhivaniya mineralov, vstrechayushchikhsya $\mathrm{v}$ pochvakh i glinakh [Roentgenograms, thermograms, and dehydration curves of the minerals encountered in soil and clay]. Moskva, Izd. AN, p. 188. (in Russian)

2. Ivanova V.P., Kasatov B.K., Krasavina T.N., Rozinova E.L. 1974. Termicheskiy analiz mineralov i gornykh porod [Thermal analysis of minerals and rock]. Leningrad, Nedra, p. 400. (in Russian)

3. Osovetskiy B.M. 1993. Drobnaya granulometriya allyuviya [Fractional granulometry of alluvium]. Perm, Izd. Perm Univ., p. 43. (in Russian)

4. Osovetskiy B.M., Moloshtanova N.E. 2013. Litologiya (klassifikatsiya, metody issledovaniya, opisanie osadochnykh porod) [Lithology (classification, methods of study, description of sedimentation rock)]. Perm, PSU, p. 158. (in Russian)

5. Rentgenograficheskiy kolichestvennyy fazovyy analiz (RKFA) glinistykh mineralov (kaolinita, gidroslyudy, montmorilonita) [Roentgenographic quantitative phase analy- sis of clay minerals (kaolinite, illite, montmorilonite)]. Metodicheskie recommendatsii №139. NKOMMI BIMS, 1999. (in Russian)

6. Ryzhikov N.I., Mikhaylov D.N., Shako V.V. 2013. Metod rascheta profiley raspredeleniya poristosti i obyomnykh doley materialov $\mathrm{v}$ poristoy srede $\mathrm{s}$ pomoshchyu analiza dannykh rentgenovskoy mikrotomografii [Method of calculation of porosity distribution profiles and minerals balk content in porous medium using analysis of $\mathrm{x}$-ray microtomography data]. Trudy MFTI, Prikladnaya mekhanika, 5 (4): 161. (in Russian)

7. Ekspressnyy rentgenograficheskiy polukolichestvennyy fazovyy analiz glinistykh mineralov [Express X-ray semi-qualitative phase analysis of clay minerals]. Metodicheskie rekomendatsii №68. NKOMMI VIMS, 1991. (in Russan)

8. Kato M., Takahashi M., Kawasaki S., Kaneko K. 2013. Segmentation of multi-phase X-ray computed tomography images. Environmental Geotechnics, doi: 10.1680/envgeo.13.00036.

9. Schluter S., Weller U., Vogel H-J. 2010. Segmentation of X-ray microtomography images of soil using gradient masks. Computers and Geosciences, 36: 1246-1251. doi: 10.1016/j.cageo.2010.02.00. 